\title{
Joaquín García Monge: derroteros y derrotas de su utopía humanista (el Credo en el Porvenir)
}

\author{
Wilbert Arguedas Pizarro*
}

\begin{abstract}
RESUMEN
García Monge representa una figura de enorme dimensión en las letras y el pensamiento costarricense y latinoamericano. Su utopía humanista tiene un anclaje fundamental en la sociedad y en los valores de esta. Así, en medio de lo ideológico, los ideales por los que aboga tienen un fuerte asidero en su producción y ello es palpable en Credo en el Povernir. Su lucha es la utopía por un mundo mejor para todos. Su pedagogismo es más que un discurso, es una acción, una visión de mundo. Pensamiento y acción confluyen.
\end{abstract}

Palabras clave: Humanismo, utopía, valores, pedagogía, Repertorio Americano.

\section{ABSTRACT}

Garcia Monge represents a great figure in costarrican and latinoamerican literature and thought. His humanist utopia has a fundamental connection with the society and its values. Therefore, the ideals for which he advocates have a strong foothold in his prodution, and this is noticiable in el Credo del Porvenir. He struggles for the utopia of a best world. His pedagogy is more than a speech, it is an action, a vision of a world. Thought and action merge both together.

Keywords: Humanism, Utopy, Values, Pegagogy.

Wilbert Arguedas Pizarro, es egresado de la licenciatura de Administración Educativa del CIDE y de la licenciatura de Lingüística y Literatura, de la cual es bachiller, ambas de la UNA, en Heredia. Se graduó como licenciado de la Enseñanza del Español en la Universidad de las Ciencias y el Arte, en San José. Profesor en el Conservatorio de Castella y profesor-tutor de Literatura e Identidad Costarricense en la Escuela de Ciencias Sociales y Humanidades de la UNED. 
...una América Unida, la nuestra, la en realidad desunida.

Hay tanto que hacer todavia en esta dirección básica, definitiva. Es deficiente la técnica del espíritu con que anhelamos hacer esta unión. Hay que perfeccionarla.(...) Es la unión en que creo, la del Espíritu.

AMÉRICA UNIDA Rep. Am. 41:22, 1944. Dic del 43. J. García Monge

\footnotetext{
Se intentará en este ensayo abordar la Utopía Humanista de Joaquín García Monge, desde su formación en el Liberalismo Radical hasta la consolidación de la conciencia de su lucha social; en su doble función de maestro e intelectual fundamentado en dos acciones, programas o proyectos.
}

La primera acción es políticocultural en la oposición entre el pueblo-nación (la clase social-popular y obrero-trabajadora, especialmente) y la oligarquía (clase capitalista-propietaria).

La segunda es entre la concepción de pueblo-nación (fundamentado en una mezcla de espíritu, cultura y raza, llamada Americanidad) contra el Imperialismo (mercantilismo y totalitarismo), a través de la acción inmediata: el Americanismo.

Estas acciones son políticamente concretas y su objetivo principal por cumplir (lograr un Porvenir óptimo), para dignificar la vida del ser humano, en la sociedad costarricense e hispanoamericana, se basa en el ideal o la utopía del Humanismo ${ }^{1}$ frente al Imperialismo o Materialismo. Ideal o utopía del Humanismo porque es un legado histórico desde la antigua

1. Sobre el Humanismo dice Savater (2000:84): Para comenzar será bueno precisar lo más posible la noción misma de humanismo. Aunque el uso original del término "humanista" y de otros conexos como studia humanitatis y res humaniores se remonten hasta comienzos del Renacimiento, la voz "humanismo" es más reciente. Fue acuñada por un maestro de escuela bávaro en 1808 y su uso primigenio fue casi sinónimo de "filantropia". A los efectos que aqui nos interesan, sin embargo, la palabra humanismo es algo mucho más amplio, que ya no denomina solamente una actitud moral benevolente o compasiva (de hecho, en el humanismo más estricto pueden inspirarse éticas poco ajustadamente filantrópicas) sino una disposición filosófica general (...) El giro humanista supone lo siguiente: es el hombre (...) por las modificaciones de la manifestación histórica de su voluntad, quien se convierte en único sustrato de los valores que orientan a la comunidad humana, sean en lo moral, en lo político o en lo estético (...) En el plano institucional, el proyecto democrático es la realización concomitante del giro humanista, cuya igualdad universal de condición entre los hombres postula y del cual instituye la perfectibilidad progresiva y el debate permanente (...): participación igualitaria en la soberanía de lo colectivo y plena soberanía autónoma individual. Aunque este esquema esté sujeto también a puntualizaciones y corrección...

Más abajo Savater resume lo anterior de esta forma: “... el humanismo no es más que el primero de una secuencia de conceptos ligados entre sí: hombre, razón, libertad, universalidad moral, democracia, autonomía (sujeto), independencia (individuo)... Seguidamente Savater advierte: A partir de los años sesenta, los pensadores más influyentes han desechado o combatido casi todos estos conceptos, desde el terreno estrictamente filosófico, antropológico, lingüístico o psicoanalítico. Este giro antihumanista suele ligarse al movimiento llamado estructuralismo, pero en realidad el debate es anterior. Proviene, al decir de Savater, precisamente 
Grecia y Roma ${ }^{2}$ que está haciéndose en la medida que el ser humano hispanoamericano, día a día, construye su universo y su destino "aquí y ahora" frente a un "allá y un después".

\author{
La primera acción es base para \\ el triunfo de su utopía: formar con- \\ ciencia social, politica y cultural en \\ una sociedad dividida en clases y ex- \\ plotada laboralmente. Triunfo que se
}

del primer existencialismo sartriano [en el sentido de que el humanismo es hacerse responsablemente] criticado por Heidegger, para quien el humanismo -incluso el romano- es una metafísica o "esencia" evidente. Más adelante Savater no acepta la opinión de Heidegger (acusado de su adhesión al nazismo) y señala: "El humanismo ha consistido principalmente en cuestionar y problematizar los sucesivos modelos de esencia humana tomados tradicionalmente por evidentes", es decir: el hombre está obligado a inventarse e instituirse así mismo a partir de su libertad...(y la de los otros: la voluntad o la libertad de la comunidad). Parafraseando lo que él mismo dice, se trata de "entender nuestro tiempo (o cualquiera otro) y condición (universal, moral, ética, cultural e histórica...): la libertad humana es el humanismo". Ello conduce, a decir de Savater, a una sociedad de individuos mejores, responsablemente autónomos y más conscientemente independientes. El resto, añade, es terror y esclavitud, muchas veces consentida.

Esta larga cita es clave, pues arroja luz sobre la utopía humanista de García Monge al teorizar sobre el origen o intentar describir el modelo utópico humanista de este pero sin forzarlo, es decir, es un ángulo o aspecto por donde empezar a descubrir qué originó el derrotero y la derrota de esta utopía. Lo importante es que el derrotero humanista se fundamenta, al decir de Nietzsche, citado por Savater (2000:98) en lo siguiente: "La grandeza humana es algo que hay que conquistar una y otra vez con lucha. Esta grandeza obtiene la victoria cuando vence en su propio pecho el ataque de la vileza (...)"

Para Savater este triunfo es el logro de la libertad. Para nosotros, por añadidura, dicha libertad fundamental no es mera compasión hacia los otros, como en el caso del personaje José Blas, en El Moto, tal como lo había señalado Seymour Menton (Quesada, 1986: 232) crítico literario de García Monge. Estamos de acuerdo con Quesada Soto (1986:227-236) quien afirma que la obra de García Monge supone radicalidad, vibración, coherencia, nueva actitud, crítica, justicia, solidaridad, lucha humanista, antiimperialismo, republicanismo, antifascismo, antinazismo..., en suma.

Al respecto, agregamos: rompimiento con la utopía patriarcal como semilla humanista y justiciera. Por lo tanto, no puede ser pura compasión o contemplación, ni siquiera estética-literaria, hacia José Blas, sino que la desgracia de este personaje, imagen de un colectivo o pueblo mancillado, es la realidad no contada hasta entonces, la otra realidad oculta y recuperada más adelante por el posmodernismo literario: el marginado como eje temático de la identidad nacional y la literatura contemporánea costarricense. Es decir, García Monge, de modo visionario, devela la falsa realidad retratada detrás de lo contado: la angustia existencial y humana de José Blas no es literaria ni históricamente aislada. Es universal y políticamente legítima toma de conciencia social por vivir una cruda desposesión, en un mundo contradictorio, al decir de Goldmann, citado por Quesada (1986:235). La huida del héroe hacia Las Salinas es una búsqueda de libertad pero habrá quien diga que este debió quedarse a luchar. Pero, al decir de Abelardo Bonilla (Quesada Soto,1986:236) también es una forma de protesta ante una serie de valores monolíticos de la incipiente burguesía.

Finalmente, esta visión crítica de García Monge hacia la sociedad costarricense, llevaba contradictoriamente su futura derrota: la incomprensión, a propósito y de manera ideológica, de su utopía desde un sector político declarado burgués.

2. La Dra. Ana Cecilia Barrantes (1996), señala en la Peroración, que "el despertar de la utopía arrancó con Alexander von Humboldt cuando comprendió a América como el "continente de la esperanza", refugio para espíritus volcados hacia el futuro, no como un elemento exótico o extravagante, sino dentro de un proceso de integración universal. En 1825, Friedrich Hegel proclamó que América "es el continente del porvenir". Como es notorio, García Monge también tuvo su "etiqueta” para América, la llamó Matria (Mutterland: concepto original de Leopold Ziegler, filósofo alemán) o, como señala la misma Dra. Barrantes, el concepto 
agrandará si la clase explotada pudiera educarse integralmente a través de la escuela, el periodismo y la lectura.

En contraposición, la derrota está fundamentada en varios aspectos:

a) en los cambios sociales, culturales, políticos y económicos, entre las décadas de 1960 y 1970 , de la sociedad costarricense e internacional así como en el cambio generacional natural;

b) y con la muerte física de García Monge en 1958.

Aquellas nuevas generaciones intelectuales, culturales o artísticas no continuaron con la problematización de la sociedad liberal-capitalista, iniciada por don Joaquín y otros intelectuales de su época, nacidos a finales del siglo XIX, y porque después de su muerte surgieron nuevos y "extraños" patrones culturales ajenos a las culturas costarricenses: tanto la oligárquica como la popular, provenientes de la incipiente posmodernidad que enfatizaba lo social y el posmodernismo enfocado hacia lo cultural ${ }^{3}$; ambas, llevadas a imagen desde la comunicación de masas promovida por el Capitalismo ${ }^{4}$. Y con gran certeza, para la propuesta principal de este ensayo, la Licda. Ramírez da en el punto con esta reflexión:

"Como se ha dicho, la posmodernidad y el posmodernismo surgen después de los años sesenta, cuando las grandes utopias no se concretaron. El presente es el único tiempo, no hay oportunidades de soñar con tiempos mejores; la modernidad estalla." (Ramirez 2006: 112-113)

Por otro lado, la alineación con las ideas revolucionarias Comunistas (para el caso de América Latina

-latinizado- de la búsqueda de una "terra incognita" y de una nueva tradición para trascender la circunstancia inmediata y buscar respuestas que nos vinculen a la gran tradición de la cultura universal. Es decir, esta idea aún tiene contemporaneidad para nosotros... Y en la Matria también cabía la utopía en los posibles frutos espirituales del alma de Oriente (...) en América (...) y España.

3. Sobre los conceptos de posmodernismo y posmodernidad, se citan aquí las reflexiones de la Licda. Ángela Ramírez G. (2006): "Posmodernidad como una socio-histórica época, posmodernismo como una configuración de arte contra la modernidad y posmoderno: el conocimiento como una crítica a la epistemología moderna".

4. Ídem ob.cit. (2006), se cita a la Licda. Ramírez para aclarar lo siguiente sobre la posibilidad que tuvo el posmodernismo y el capitalismo para abonar parte del fracaso de la utopía humanista de García Monge por lo siguiente: "La modernidad se propuso conquistar el mundo en nombre de la razón, la certeza y el orden social, los cuales se asentarian sobre una nueva base económica: el capitalismo (...) El posmodernismo significa, por tanto, un desencantamiento con la modernidad y su concepción de mundo (...) Hay una pérdida de confianza en la idea del progreso y en el futuro que depara tiempos mejores... No existe ya un horizonte de universalización, de emancipación. La modernidad entra en crisis porque su principal fuerza legitimadora, el historicismo, se rompe." 
especialmente en Cuba) intentan llenar ese vacío utópico con un esquema pos-socialista 5 .

También, ambas ideologías se encargaron de promover disputas sangrientas dentro y fuera de América Latina, a favor de sus intereses, con un contenido Humanista difuso. En el Siglo XIX y XX, el capitalismo promovió un cambio social evolutivo, lento, natural y apegado a principios religiosos conservadores, desde arriba. El comunismo hizo lo contrario: cambios rápidos, revolucionarios y laicos desde abajo. Esta "dicotomía" es reduccionista entre el bien y el mal. Toca abstracciones heterogéneas entre lo bello, lo verdadero, lo útil y bueno(mismidad) frente a lo feo, lo malo, lo inútil y lo malo (otredad). A la vez, estas oposiciones transitan de forma crítica por el grado de espiritualidad que está acorde con el Credo en el Porvenir en García Monge. Pero este Porvenir (que no es ilusión e idealismo contemplativo) puede leerse en su Presente. Entonces García Monge no es una especie de romántico desfasado sino un intelectual claramente juicioso.

Para que quede más claro: la Utopía del Credo en el Porvenir es
Idealista no contemplativa -se insiste-, asociada al Espíritu, debe hacerse o crearse, es autónoma y no esperar que sea el Materialismo, especialmente en el Imperialismo yanqui, el que construya ese Porvenir, tal como lo crítica García Monge. Igual trasfondo se haya en Salutación del Optimista de Darío.

Esa cognición en un sentido ahora filosófico, pasa por grados de espiritualidad en varias formas básicas: artística o estética; filosófica y pedagógica; económica; cultural y ética. Todas son constante o leiv motiv en el pensamiento y la obra de García Monge (García Carrillo, 1962). Se cuestionan cuál sociedad y en cuál marco ideológico, cultural, espiritual y otros, se plantea la Utopía Humanista de una mejor y digna sociedad costarricense e hispanoamericana.

Volviendo a las posturas antagónicas, la figura de García Monge, para algunos estudiosos de su obra, se ve como Anarquista-Intelectual y Político-Socialista ${ }^{6}$. Para otros, es más un utópico Humanista y Americanista que otra cosa, en las facetas de maestro, periodista, conferencista junto con la labor estética.

\footnotetext{
5. Según la Licda. Ramírez (2006, 112), El prefijo "pos" viene a significar "vivir después". "Y después significa que ya no hay normas válidas, que las virtudes han desaparecido y que, por un lado, las personas actúan de modo instrumental mientras que por otro encajan en roles y requisitos externos e institucionales sin tener en absoluto ninguna motivación moral intrínseca."
} 
En este ensayo hay inclinación por la segunda forma. Eso sí, no queda descartado que el sentido de Humanismo, en don Joaquín, es filosófico y social; aunque no es la misma época, sí es la misma esencia a la que se refiere, al conjunto de actividades realizadas por los intelectuales europeos, como Bocaccio, Erasmo, Petrarca, durante el Renacimiento, para conocer, reconstruir e imitar en lo posible las culturas clásicas: Grecia y Roma. Es decir, no fue tomado a la ligera por él. Fue formándose en un largo proceso ideológico, sociológico, histórico, literario, político, educativo y altamente reflexivo. En este sentido, al citar a tres representantes del pensamiento Humanista de la Edad Moderna, lo que se está diciendo es que el Humanismo de García Monge es inicialmente Estético ${ }^{7}$. Para él, entonces, su pedagogía se circunscribe en la preocupación por el destino del ser humano en el universo hispanoamericano, es decir, es una pedagogía secular o de este mundo, fuera del canon religioso, lo que le trajo algunos inconvenientes en Costa Rica con los Humanistas cristianos que lo consideraron Humanista neopagano.

El que sea secular o terrenal no contraviene lo Espiritual. Pues el sentido que tiene en García Monge es más cercano a lo sensible que a lo místico. Es más cercano al grado de nobleza y preocupación por lo humano que por lo celestial, sin que lo celestial se desdeñe en tanto no sea para manipular a las clases explotadas.

Un principio de este Humanismo en García Monge es la concepción laica y fuertemente terrenal. Es decir, una renovación espiritual, civilizatoria, hacia formas de vida más libres y autónomas. Sin esta base, que se vislumbraba ya como un adelanto Vanguardista ${ }^{8}$, no hubiera sido posible que él arribara a una visión crítica de la sociedad costarricense principalmente, la cual era cerrada y absorbentemente religiosa. Rescoldos coloniales que sostuvieron a la oligarquía del siglo diecinueve y veinte.

Sin embargo, lo que llama la atención es que del Anarquismo, como

6. Sobre la posición de Político-Socialista es bueno advertir que esta es una etiqueta más para desprestigiar a García Monge. Por un lado él rechazó el premio al que lo postuló Pablo Neruda, el de Stalin. Este significaba un giro político que García Monge no quiso asumir ante la mirada de la burguesía nacional. Sin embargo, está claro que ser un hombre de letras y de cultura no significaría ser buen hombre políticopanfletario. Otros intelectuales y artistas abiertamente sí asumieron posiciones políticas totalitaristas de derecha o izquierda sin pensar en el qué dirán: Lucáks, Louis Aragón, Neruda con Stalin, Heidegger con el Nacional Socialismo alemán, García Márquez con Castro, Gabriela Mistral con la derecha chilena, etc. No se les niega su categoría literaria o intelectual.

7. Al respecto, la Dra. Barrantes de Bermejo (1996), en la Advertencia de su estudio, dice lo siguiente: "El "Repertorio Americano" plantea desde su primer número la cuestión de la identidad histórica como emoción estética para abrir la aventura a una empresa ontológica de raiz política temporalmente desbaratada en la realidad". 
ideología, también puede provenir una utopía del ser humano en estado libre, puro, cooperativo, solidario y espiritualizado. Tal parece ser la misma ideología que tomarán entre los años de 1960 a 1970 los grupos juveniles de Hippies en Norteamérica desencantados por las políticas intervencionistas militares en Vietnam. Ideología que no se pudo sostener sin un programa sólido tanto en lo filosófico como en lo ideológico y político.

Esto significa, a manera de hipótesis, que las nuevas generaciones no intelectuales populares y burguesas costarricenses, posteriores a la muerte de don Joaquín, pudieron adoptar esa visión anarquista sin orientación social (mediatizada por la cultura de masas y el rock-pop como toque seudo estéticoespiritual referencial: la famosa directriz paz y amor) más fácilmente que continuar el modelo utópico Humanista y Social de García Monge, modelo que sí trataron de seguir los intelectuales y escritores de los años 1960-1970 e incipientes grupos juveniles revolucionarios en la U.C.R. y más tarde en la U.N.A., en aras de una sociedad justa, libre y humana?.

Rafael Cuevas (1995:108) dice al respecto que la Revolución Cubana y la onda Hippie son nuevos valores que irrumpen en el campo cultural costarricense hacia finales de la década de 1960 y principios de 1970. La

8. El concepto de Vanguardismo que se deslinda aquí es en la línea política y social y en la artístico-literaria (Monge, 2005); no obstante, hubo una "trasgresión estética (desafiar un canon) y una ideología de la historia"... El binomio letras/política -es decir éticalestética- fue uno de los resultados del vanguardismo literario. Agregamos nosotros: esta es otra semilla de la futura derrota de la utopía humanista de García Monge. Más adelante, el mismo Carlos Francisco Monge generaliza con esta advertencia: Pero el costarricense fue un movimiento de bajo perfil en lo histórico-social y lo histórico-literario. En cuanto al primero, dice este autor, los movimientos sociales, de reivindicación social y política fueron en Costa Rica principalmente civilistas; en cuanto al segundo, la confrontación ideológica entorno a aspectos literarios fue confusa tanto para combatir o defender.

9. Arnoldo Mora (Cuevas, 1995), da claridad sobre lo expuesto en este apartado de nuestro ensayo, y escribe lo siguiente: "La comprensión de los hechos históricos solo es posible si tenemos lúcidamente presente, a guisa de contexto, el trasfondo politico dentro del cual se dieron. La mayor parte de la época que estudia Cuevas (se refiere al libro El punto sobre la i, la observación es nuestra) y pertenece a lo que genéricamente se ha llamado la "Guerra Fría", caracterizada por una polarización ideológico-militar que abarcó hasta el último rincón geográfico y social del planeta, al igual que la totalidad de las actividades humanas".

Por otra parte, Mora descifra la hipótesis de Cuevas, y de paso ilustra lo que nuestro ensayo intenta dilucidar, en cuanto a que los grupos beligerantes se enfrentaron al Estado costarricense y a los sectores socioeconómicos que lo homogenizaban. El Estado trató de legitimizarlos o cooptarlos al aprovecharse de la evidente debilidad de esos sectores. Cosa que ocurrió pues sus mismas carencias los obligaron a refugiarse en actividades financiadas por el mismo Estado. Rafael Cuevas, dice Mora, logra con esto explicar la ambigüedad de la conducta de esos grupos. A nuestro parecer, esto explica, pues, porqué el Proyecto de García Monge fue decididamente debilitado una vez más por la burguesía y la Iglesia Católica de ese presente histórico, lo cual da pistas para referirse a la frustración utópica en García Monge, según se deduce en la cita número cinco de estas notas, de la Dra. Ana Cecilia Barrantes de Bermejo y la cita número nueve de Iván Molina. 
Revolución Cubana contribuye con el nacimiento de los grupos contestatarios, simpatizantes, algunos, del Partido Vanguardia Popular o el Partido Comunista (o "la nueva izquierda"), frente a la cultura "oficial" o Estatal, integrada, dice Cuevas, por los "hombres de letras" del Partido Liberación Nacional que "abraza" la Alianza para el Progreso como opción ideológica.

Por otro lado, sigue ilustrando Cuevas, hubo fisuras en el Partido Liberación Nacional, como la conformación del grupo Patio de Agua que aglutina a intelectuales como Isaac Felipe Azofeifa, los cuales descubrieron que los planteamientos de Liberación ya eran insuficientes para el mundo de entonces.

Las utopías, los valores e ideales nacidos en Europa, en Inglaterra con el Liberalismo Positivista, impulsan a García Monge a moverse hacia Nuestra América, hacia adentro, con su universal Repertorio Americano, así como el resto de su obra y acción Humanista, base fundamental de su Ideario. El Humanismo en García Monge es la expresión Cultural y Espiritual de una renovación histórica postmoderna que se manifiesta en todas las actividades humanas, como la política, la técnica, la literatura, la comunicación y la pedagogía, entre muchas otras. Es una necesidad de libertarse de viejas tradiciones sociopatriarcales con un despertar del ser humano a una conciencia de sí mismo, como constructor de grandes transformaciones de una nueva civilización, con dignidad y sentido terrenal; de ahi lo laico, no por simple oposición al dogma religioso que considera lo terrenal como transitorio y que lo perfecto o sublime viene a darse con la huida del mundo.

El sentido terrenal o laico, la ligadura con la Madre Tierra, no es un sentido totalmente irreligioso y anticristiano, aunque algunas cosas en el Humanismo así lo sean. Lo cierto es que en don Joaquín hay una íntima religiosidad, sin ser mística, con una fuerza en que se siente la personalidad del ser humano y la presencia de lo divino en ella y en el mundo terreno (es ver a Dios en el Mundo); es donde se realizará la obra Americanista, conectando así el Ideal Utópico con lo concreto terrenal, donde el ser humano es el centro y el motor de Hispanoamérica y de la sociedad costarricense.

Sin embargo, esta concepción fue desvirtuada por la Iglesia católica conservadora del momento, al acusar a don Joaquín de "ateo y comunista". Él ya había previsto ataques así. Por eso rechazó el Premio Stalin de la Paz que le ofreció Pablo Neruda. No quería "ser piedra de escándalo por acá". No disfrutaba de suficiente libertad, según le manifestó a Joaquín Gutiérrez en una carta inédita del 3 de octubre de 1952. Entonces, la fórmula de la Iglesia era simple; para ella el centro y motor de la historia es Dios y no el hombre; es la Biblia y no 
las letras humanas; es el cielo y no la tierra; es la fe y no escudriñar ${ }^{10}$.

Formular una utopía en García Monge es verlo también como un ideólogo, lo cual se ve en su experiencia docente formal e informal, en Costa Rica y fuera de ella. Su utopía no lo convirtió en un soñador romántico buscando un Paraíso perdido sino en un Maestro Humanista, a quien la pedagogía viva, como herramienta intelectual, le ayudó a traducir su pensamiento de manera estructurada y metódica con lo cual, como buen maestro que era, enseñó, repitió, divulgó y fomentó el anuncio de una realidad distinta mediante un método y la tecnología más eficaz de su época: el periodismo escrito y cultural del Repertorio Americano.

Reafirmando, hay en García Monge una conciencia del papel del intelectual como "una voz en el desierto" luchando por una nueva y digna vida fuera del contexto de las clases poderosas. Al respecto está su artículo "El arado y la pluma" (1905), en donde escribió acerca de la relación adyacente del intelectual con la clase trabajadora, en tanto arado y pluma son instrumentos civilizadores para obtener sustento y la conciencia de fuerza, dicha y perfección en un aquí y ahora.

Esta relación laboral: intelectofuerza está íntimamente ligada a la concepción de lo popular y lo nacional, es decir, que el pueblo también piensa y trabaja dignamente. En este mismo artículo él define la educación oficial costarricense de 1905 de cátedra sumisa, rutinaria y dogmática; el periodismo lo ve sin ideas, escandaloso, perjudicial y envilecido.

\section{En el plano formal de la educa-} ción, don Joaquín se preparó en Chile, en la época de efervescencia universitaria en lo político e ideológico, impulsado por el desarrollo del Liberalismo internacional y nacional en aspectos como: a) conciencia de un Estado y una identidad nacional postcolonial para cada "parcela" de Hispanoamérica y b) frente a la primera crisis del Capitalismo internacional que dará, años más tarde, como resultado la Primera Guerra Mundial; c) por otro lado, la reforma liberal universal en la

10. Iván Molina en Anticomunismo Reformista (2007) aclara la cuestión religiosa del momento histórico que enfrenta a García Monge con la Iglesia, así como esta contra los judíos (que no eran bien vistos por no ser una raza nacional) que vinieron de Polonia manifestando un claro interés eclesiástico por el fascismo. Luego, entra en contradicción frente a la ideas de vanguardia que resaltaban el papel social manifiesto de elevar a los trabajadores de nivel para obtener votos, lo que generó la alianza de Calderón con los Comunistas, y puso en alerta a la embajada de Estados Unidos. Y más confuso fue el panorama para la legación de ese país al ver los ataques de la iglesia contra los judíos y asociarse a la alianza Caldero-Comunista en 1941. El resultado fue un anticomunismo de carácter social -y no solo de la iglesia, que inventó sindicatos clericales o católicos "independientes", sino de la burguesía para no quedarse por fuera en un intento falso de compromiso; bien lo ilustra Molina, también fue para acortarle alas al movimiento de León Cortés Castro. Para cerrar con broche de oro, años más tarde, en 1948, el figuerismo arrasó con todo y se apropió de los proyectos sociales hasta 1948. 
escuela primaria, obligatoria, gratuita y laica. Sin embargo, este trípode pronto se desvirtuó porque los mismos padres de familia desobedecieron el mandato legal y penal si no enviaban a sus hijos a estudiar; el Estado declaró que no tenía presupuesto; la iglesia católica se alió al Estado y controló la enseñanza religiosa contando con el beneficio económico estatal, aunque inicialmente existió un divorcio entre la iglesia y el Estado liberal.

La experiencia chilena del contacto con el Liberalismo Radical o Crítico (al que don Joaquín identifica con la Democracia) frente al Liberalismo Clásico o Conservador (al que identifica con el materialismo económico responsable de la desigualdad social); fue el punto de arranque para su ideario progresista, con un eje fundamental e inamovible: la lucha social, lo cual delineó la Utopía del Credo en el Porvenir: libertad, equidad, dignidad, intelectualismo, y como centro de su credo político: antiimperialismo y antidictaduras, lo que le dio una identidad particular a su labor de ideólogo, maestro nato y de hacedor de cultura, aspectos que ya se señalaron en este ensayo.

Aparte de la formación chilena, no hay que olvidar que García Monge tuvo sus raíces como maestro con los mismos moldes de sus predecesores quienes amaban y disfrutaban los tesoros de la cultura humana. Eran iluministas, letrados o intelectuales interesados en las grandes obras de los grandes espíritus del pasado, fueran estos, a decir de don Joaquín, de cualquier nacionalidad, tanto norteamericanos como hispanoamericanos. Los viejos maestros que formaron a don Joaquín despertaron en él la sensibilidad y la pasión por la historia universal, la literatura, la ciencia, la tecnología, etc., todo lo cual llenaría después las páginas del Repertorio Americano.

No se puede entender la obra total de García Monge, un hombre de acción, sin una utopía ${ }^{11}$. La suya fue consolidar el ideal de América unida, libre e independiente. Al respecto está el artículo epigráfico citado en este ensayo, "América Unida" de 1943. Por ello, es un ideólogo y conductor investido en tres áreas fundamentales de su acción: pedagogo, literato y periodista, luchando contra dictaduras e imperialismos (el de Estados Unidos o el de Rusia); a favor de estados democráticos; del americanismo como valor espiritual y sentimiento de raza mestiza que enlaza al continente frente al materialismo sin alma; de la enseñanza

11. Leonardo Merino (en Cinco Ensayos sobre Nuestra América, 2005), dice: Como se expresa en el pensamiento utópico, la construcción de mundos ideales acompaña la creación intelectual humana desde sus inicios. El anhelo de transformación de las condiciones propias de la vida en sociedad ha inspirado las artes, la filosofía, las ciencias y el pensamiento social (como en García Monge, agregamos nosotros) que, a través de sus manifestaciones, son expresión de su época y de los sueños a los cuales es sensible todo grupo humano (porque) las utopías son una construcción colectiva (no necesariamente estética) para facilitar la convivencia, sustentada en un plano ideal difícilmente concretado en la Historia. 
laica (vestigio del viejo Liberalismo) y popular; la difusión cultural: literaria, científica y filosófica, inspirado del Repertorio Americano de Andrés Bello. Su acción tendió a educar, a guiar al pueblo hacia la democracia convirtiéndose también en político pero no en politiquero. Instruyó diciendo cómo tiene que ser un político genuino, incluso escogiendo autores extranjeros como modelos para formar un espíritu auténticamente americano. Utopía también basada en la dignificación del ser humano y su condición sociocultural. Don Joaquín mismo decía que los mejores dirigentes políticos de una nación debían ser intelectuales.

Utopía es su concepto de Americanidad espiritual y sentimiento de raza; su modo de realizarla o su acción utópica es el Americanismo, términos que no son suyos originalmente sino nacidos en el Liberalismo Crítico, del que no se apartará don Joaquín desde su juventud y que son motores de su acción humana, de justicia y de projimidad.

Utopía es una sociedad futura e inexistente, sociedad que en el presente no tiene lugar. Utopía no es, pero se supone que debe ser valiosa y deseable: igualdad y fraternidad, otra fuente de inspiración de don Joaquín. Por idealista e inexistente la Utopía en don Joaquín fue una alternativa imaginaria y estética contra los males sociales de su época y que presagió para las épocas venideras, en donde está lo escabroso de su ideario. La utopía se tiene por posible. Sin embargo, para sostenerla debe existir un programa político e ideológico completo como en Martí o Bolívar, sin olvidarse que ellos se sostuvieron en las armas. García Monge se sostuvo en las suyas: letra, cultura y educación, inspirado en Bello ${ }^{12}$. Pero no fue suficiente en su época aunque podría ser en otra. Podría ser... Pero se insiste- no fue. A manera de símil ilustrativo, García Monge, como don

12. La influencia de Bello en García Monge ha sido documentada por el mismo García Monge. Arnoldo Mora (2006:289-293), al respecto señala una idea de fondo que explica, de forma general, tal apreciación de García Monge, la de asumir como prioritaria la tarea de pensar en nuestra realidad usando nuestra propia lengua. De ahí -enfatiza Mora- debe partir la conciencia de nuestra identidad. Pensar en la lengua castellana -hecha nuestra por razones de cultura e historia, aclara Mora- es hacerlo sobre la realidad que nos rodea e igualmente es pensar en nosotros mismos, como un microcosmos, no como españoles ni como indígenas, al decir de Bolivar.

De esta forma, si hubo emancipación política también lo hubo en lo cultural, añade Mora. Entonces se enfoca en Andrés Bello como "el primer pensador posterior a la gesta emancipadora (...) Es el creador (...) uno de los más importantes estudiosos de nuestra lengua, el pionero, el imprescindible, del conocimiento del español de nuestra América (...) Con esto Bello pretende continuar la gesta libertaria de Bolívar, pero estudiando nuestra lengua". Luego, Mora dice que donde fracasó la campaña de Bolívar (la unidad americana) -la utopía, como en García Monge le agregamos-, la cultura y la lengua iban a triunfar con Bello, quien fue científico del lenguaje, añade Mora, influido de manera ecléctica por el racionalismo cartesiano, el empirismo inglés y emotividad escocesa. Entonces, de manera clara, García Monge emprende la tarea cultural y lingüística con el resultado que hoy se conoce. 
Quijote de la Mancha, soñó con una Edad de Oro en una Sociedad de Hierro. Es decir, no se puede vivir sin una utopía, un ideal, un credo aunque la realidad sea otra o sea excluyente.

Él decía que para que su utopía se cumpliera debía estar en manos de los maestros y profesores, secundada por los estudiantes, periodistas, editores y escritores. En suma, una élite intelectual. Ellos debían enseñar que el camino empezaba conociendo a "las figuras próceras de esta cosa grande y sacrosanta que llamamos América" ("Unidos por la Cultura", 1944), que había que citarlos y constantemente leerlos con cuidado. Como maestro nato trata de despertar conciencia del ser hispanoamericano, que se conozca su realidad y se defienda su suelo para orientarse hacia el Porvenir (credo y utopía noble y profética por reveladora), la concordia, la cooperación, la solidaridad.

Pero no se debe mirar al hombre que lleva a cabo este ideal, sino a la obra práctica y al discurso utópico que lleva adentro. Basta con leer el ensayo “Unidos por la Cultura". Sin embargo, fue el de don Joaquín, un intento que fracasó por inacción de la misma sociedad escindida, primero oligárquica, militar (antes de 1948) y, contradictoriamente, liberal; después, burguesa o capitalista, que lo tenía como un hijo desconocido en sus adentros y lo desterró ante su discurso, en tanto que utópico, artístico y cultural, inflamado de humanidad, ideales legítimos y justicia. Fue la misma sociedad que, al darle el poder político a la Asamblea, negó el derecho a ser diputado y candidato a la Presidencia de la República, después de la llamada Guerra Civil de 1948

Este hecho no debe quedar sin referencia en el análisis profundo del esquema ideológico de García Monge en futuras investigaciones. La "Guerra del 48" fue un hecho revisado y desmitificado claramente por Rodolfo Cerdas (1998) La otra cara del 48, en el que el papel de Estados Unidos, en el inicio de la Guerra Fría, así como la sombra del General Somoza, entre otros intervencionistas extranjeros, fueron un acicate para el triunfo del figueroulatismo (capitalismo criollo) frente al calderocomunismo (movimiento obrero).

Lo expuesto en los párrafos precedentes es otra contribución al triunfo y el fracaso en la utopía de don Joaquín, que intuye ocurrirá. Se debe volver a citar el artículo "América Unida". Él insistió en que la desunión y el distanciamiento espiritual alimentarían la autodestrucción y la pérdida de soberanía, lo que se convertiría en camino llano para que el imperialismo se asentara en Nuestra América. Aquí se muestra don Joaquín como un gran pedagogo, a través de la insistencia, la repetición de los proyectos políticos, culturales y espirituales (utópicos también) señalados en el apartado introductorio, para instaurar en otros con la finalidad de cambiar su mente, buscando diferentes perspectivas en diversas ocasiones y lugares para dar la lección más significativa: crear patria, crear 
conciencia, educar al pueblo desde su labor de periodista más que en la de pedagogo en las aulas; como fue, de verdad la suya, una cátedra universal: El Repertorio Americano.

Aparte de los elementos ya señalados, que marcaron el fracaso de la utopía de García Monge, y que se produjeron en el contexto costarricense e internacional, se pueden enunciar otros:

- No tuvo un seguidor o un discípulo que propagará sus ideas. Aunque admiradores tuvo muchos. Tal vez tuvo un vocero en su hijo el Dr. Carrillo o su amigo Luis Ferrero.

- Hubo acciones políticas mal intencionadas que tergiversaron su mensaje. En 1948 le fue negado el derecho a ser elegido diputado y a ser candidato a la Presidencia de la República de Costa Rica.

- El oficialismo costarricense, de forma real o supuesta, olvidó a don Joaquín. Todos sus cargos públicos fueron revocados y su hogar-oficina-taller fue visitado varias veces por la policía.

- Las nuevas generaciones "obviaron" el significado de la Utopía en el mensaje de García Monge "porque estas no se concretaron" (Ramírez, 2006, 113); no fueron lectores del Repertorio Americano aunque sabían que existió.
No entendieron cuál era el nuevo orden sociocultural basado en la alternativa humanista; por eso también el Repertorio Americano fue desaprovechado como la piedra de toque $\mathrm{o}$ arranque para aspiraciones nacionales políticas, culturales y educativas desde abajo.

- Las nuevas generaciones culturales y literarias de los años 60 y 70 , parece que se asignaron tareas distintas a las de don Joaquín. Al menos, parece que estas intentan desvirtuar lo legendario y terminar con los mitos de nuestra cultura. Pero algunos intelectuales se vuelven hedonistas (predominio de la imagen publicitaria y los valores de las estrellas de la farándula) y trascendentalistas rayando en un nuevo paradigma neoliberal político y cultural.

- Se habla del fin de las utopías que sostienen la existencia humana, del fin del arte y del humanismo. Son parte de los sentimientos del desencanto que dan pie al impulso posmoderno. "Hay una pérdida de confianza en la idea del progreso $y$ en el futuro que depara tiempos mejores, el desarrollo de las tecnologías se vuelve un medio para incrementar la enfermedad, no para acabar con ella" (Ramírez, 2006).

- Algunos jóvenes artistas e intelectuales, burgueses o no, como 
jóvenes adolescentes rebeldes contra su maestro e ideario, pensaron en el fin de la "leyenda" utopista y se volvieron más "Light", pues la tecnología audiovisual trajo el modelo de otras culturas como la norteamericana e inglesa, de conductas atípicas como el rock, el arte pop, los poetas del undergraund, entre otros. Esto incidió en "el deterioro de la cultura costarricense" donde se impuso patrones culturales externos en contra de la propia identidad, lenguaje, mentalidad, cosmovisión y hábitos cotidianos, incluso. Es el auge de la cultura de masas y la fragmentación de la identidad nacional como proyecto políticosocial e ideológico. Modelos impuestos desde arriba. Los sueños de gloria y celebridad son importados por la televisión incipiente en Costa Rica (años 60-70).

- En 1968, dice Ramírez (2006), "se dan los movimientos de juventudes, los hijos e hijas se revelan ante la autoridad patriarcal, se da la guerra de Vietnam, el movimiento hippie y los Beatles, la Primavera de Praga, la invasión a Hungría; se está gestando una nueva era (...) Esta fue una generación desilusionada, porque las metanarraciones o metadiscursos $^{13}$ que pregonaban la utopía de un mundo distinto fracasaron." Para Agnes Heller, citada por Ramírez (2006): "El posmodernismo fue la creación de la generación de la alienación desilusionada con su propia percepción del mundo."

- Las universidades se volvieron focos del "populismo" y empezaron el viaje hacia el mercantilismo (universidades privadas), alejadas de toda criticidad y ética humanista. Dejaron de ser élites culturales y guías del desarrollo. Es decir, las juventudes universitarias encontraron que no tenían respuestas a los retos de su época y el poder dominante se sirvió de eso para desviar la realidad juvenil de esos universitarios con fanatismos religiosos, deportivos y fetichistas.

- También se creó un desencuentro con la realidad al imaginar una Costa Rica diferente al resto de las naciones centroamericanas, con lo que se desvirtuó el paradigma del espíritu de Unión (Totalidad) Americana y centroamericana presionado por los intereses mercantilistas extranjeros

13. Al respecto Ramírez (2006: ), dice: “Son metanarraciones o metadiscursos: los discursos que, partiendo por lo general de una sola disciplina, sin diálogo serio con los aportes de las demás, pretenden encerrar en si y dar conocimiento de la realidad." 
(años 60-70), donde se establece el fragmentarismo como visión ideológica de esta región.

- En educación se logró distanciar a la escuela de la vida real, al desarraigo del ser humano (deshumanización) y del contexto que la circunda ${ }^{14}$. Esta fue pasiva, memorística, enciclopédica y uniforme, beneficiando los intereses ideológicos y políticos de la burguesía nacional y del Estado Centralista (años 60 y 70), con lo cual la educación se concibió para el desarrollo capitalista y técnico con modelos Norteamericanos y de Europa.

- Pero, este ideal humanista tendría en las nuevas generaciones un enemigo feroz cuando lo que se debía enseñar (contenidos escolares programáticos humanistas) le dio lugar al cómo hacerlo (técnica, método, guía...), y a este nivel escolar se le suma el nivel social en el que lo que vale es el estatus económico en las relaciones sociales, no lo que tiene de humano una relación social.
- El pedagogismo enterró el mito humanista. Fracaso palpable de la Utopía de don Joaquín en la que la rapidez del cambio de vida no permite saber muchas cosas sino especializarse en una. La especialización enterró también los estudios generales o de humanidades en las universidades privadas. "Hay un repliegue a la vida privada" (Ramírez, 2006). Por ello, aquí no se cumple el ideal del estudio de las ciencias exactas y naturales con espíritu humanista. A partir de los años sesentas, la fe en el progreso se derrumba; la otra cara del industrialismo se reveló amenazadoramente (Ramírez, 2006).

- No se logró concretar un currículo latinoamericano o una tradición pedagógica americana obviamente centrada en el sujeto histórico latinoamericano: indígenas, campesinos, obreros, mujeres, sectores populares urbanos, y otros, tal como lo concibió Bolívar, Martí, y el mismo García Monge. Es decir, concretar el encuentro entre escuela y

14. Sobre este aspecto de la educación dice Carlos Rojas Osorio (2004): "La educación moderna, recalca Lipovetsky, mantenía unida la religión del deber, la ilustración y el progreso moral de la humanidad hacia la emancipación". Sin ser una copia de tales idealismos, los intelectuales costarricenses defendían estas posturas pedagógicas, entre ellos García Monge. Sin embargo, dice Rojas Osorio: "Hoy se habla mucho de la ética; las democracias actuales la reclaman, pero no es ya la ética del deber, ni la renuncia a sí mismo, sino una moral indolora propia de la era individualista". Quizás esta cita, agregamos, es otra prueba del fracaso en el derrotero de García Monge hacia una sociedad mejor, libre y responsable. 
realidad nacional y continental como lo intentó hacer la Pedagogía del Oprimido (años 60).

- Hispanoamérica ve perderse posibilidades de grandeza que se malograron en el pasado indígena. Ronda la pregunta: ¿cuál será el destino de Hispanoamérica?

- Hoy ya no es lo mismo que ayer, "sin mito", descontentos, viviendo la antiutopía o la realidad de una Hispanoamérica sin Credo en el Porvenir. "El presente es el único tiempo..." (Ramírez, 2006).

- La antigua sociedad oligárquica costarricense (hoy burguesa) continuó y continúan con su proyecto de escisión social (incluso resistiendo diversas crisis del capitalismo) en la que los trabajadores e intelectuales ocupan lugares subordinados y se fundamenta en el mito de una igualdad o una democracia sociopolítica ocultando el verdadero carácter clasista. No se logra, pues, desmitificar el sistema democrático costarricense tal y como lo intentaron hacer Mario Sancho, Omar Dengo y Vicente Sáenz, quienes vieron en este sistema una exclusión de las clases populares a las cuales se les mantenía subordinadas, marginadas, manipuladas y explotadas.

- Se quiera o no, la realidad de Hispanoamérica se perfila fragmentada, hasta hoy día, con la Revolución Castrista, el incipiente intento militar-socialista de Hugo Chávez y se tergiversa la utopía del unionismo y el americanismo frente al yanquismo, torciendo la imagen de Martí y Bolívar, en aras de un totalitarismo extranjero como el comunismo; utopía que se mantiene viva en círculos juveniles revolucionarios, protestatarios y radicales paradójicamente dentro y fuera de las universidades financiadas por Estados oligárquicos o capitalistas (Cuevas, 1995). Utopía en la que se matriculó la escuela de Freire con la Pedagogía del Oprimido basada en la doctrina revolucionaria de la liberación, de lo dialógico, la autogestión y de la relectura del legado del modelo educativo cubano, en la Pedagogía de la Esperanza, del incompleto proyecto sandinista iniciado en los años 70 e inspirado en aquel viejo y genuino, pero manoseado, emblema de Sandino libertador ante la dictadura de Somoza ${ }^{15}$.

15. Al respecto dice Ramírez (2006): "Las metanarraciones de los contramodelos modernistas como el socialismo crearon expectativas por las que muchos hombres y mujeres murieron, sin embargo, se diluyeron $y$ se convirtieron, como apunta Lyotard, en narrativas históricas." 
Con todo ese panorama desplegado antes de su muerte, un año después de ella y, por lo menos, una década y media después, se insiste en que su fracaso no fue total pues dejó la idea de fundar un nuevo (y utópico) orden social, económico, cultural, humano y libre.

Por lo tanto, tampoco se puede decir que fue una utopía ingenua pues él sabía lo arduo de la acción para conseguirla; o quizás, los medios no eran lo suficientemente poderosos para lograrla y que otros, las nuevas generaciones, con instrumentos o tecnologías más sofisticadas podían llevar adelante lo que él soñó: la Nueva Arcadia frente al capitalismo irracional y falto de espíritu. Pero las nuevas generaciones se encontraron vacías y desorientadas, sin mitos, frente a una realidad que, contradictoriamente, reclama una utopía, un ideal, un objetivo.

Un cierre, no una conclusión definitiva. Lo que motivó a escribir este ensayo fue la idea de procurar que las actuales generaciones sepan quién fue don Joaquín García Monge y cuál fue el legado que dejó no sólo a los jóvenes del Cantón de Desamparados, en San José, sino a toda Costa Rica, jóvenes que deben tomar la bandera que don Joaquín dejó desplegada en la conciencia de una nación y un continente libre y no-inquilino en su propio suelo, de cualquier fuerza extranjera, como él mismo lo advirtiera alguna vez.

También, saber contemplar, en don Joaquín, la actividad socioideológica, política, humana y educativa, en síntesis: cultural y espiritual que, como lo dijera su hijo, el doctor Eugenio García Carrillo: "Cultura y Espíritu son leiv motiv en don Joaquín". Porque en los días en que vivió, don Joaquín no fue del todo comprendido en su mensaje (muchas veces fue tergiversado a propósito) y ni él pudo evaluar los resultados de su ideario, de su credo, de sus conquistas que hasta hoy incluso muchas están por descubrirse dado el monumental y apasionado producto histórico y cultural que dejó y que lo superó a sí mismo, sin que él se lo propusiera, aunque pudo entrever o presuponer su futuro; por eso, se puede decir que el valor de su obra, al sobrepasarlo como individuo histórico, es universal, y eso, todavía hay mucha gente en Costa Rica, que lo ignora y se puede estimar esa situación como un fracaso, pues a don Joaquín no se le "venera" en Costa Rica como a Martí o a Bolívar en otros países. Una razón es la exclusión ${ }^{16}$ que la sociedad oligárquica hizo a propósito

16. Dice Ramírez $(2006,118)$ : “...los pueblos latinoamericanos comparten pobreza y exclusión social (...) Ya es hora de que los Estados latinoamericanos (...) rompan de una vez por todas con la concepción moderna de exclusión de las mayorías". 
de él, al contrariar este los intereses capitalistas de aquella. Tal fortuna le aconteció a Bolívar ${ }^{17}$, no así a Martí1 ${ }^{18}$.

Por otro lado, es necesario saber penetrar con mayor profundidad en las fuerzas sociales e individuales que impulsaron la utopía (que es una especie de lema más que una realidad, como la libertad frente a las dictaduras, según el peruano Luis Alberto Sánchez) de este insigne maestro de la educación formal y no formal. Ejemplo de visionario que, a manera de ilustración, propuso que se creara la regionalización educativa de Costa Rica y no fue sino hasta 1982 cuando ocurrió.
Queda claro que en García Monge la característica principal de su pensamiento fue el reformismo en muchos aspectos de la vida como lo cultural, lo social, lo educativo, lo espiritual..., con ideas multidimensionales y proféticas en las que hay inicios anarquistas, liberales disidentes, socialistas y, obviamente, preveía la llegada del posmodernismo ya examinado en este ensayo en algunos de sus alcances, aunque su idea principal y unificadora era la oposición y cuestionamiento contra el Estado oligárquico-liberal y el totalitarismo en cualquiera de sus manifestaciones: capitalista o comunista, con lo que su acción

17. Arnoldo Mora op cit. (2006) ilustra con claridad la conjetura tratada en este ensayo. La utopía humanista de García Monge fracasó, pero abrió un camino, tal como aconteció con la de Bolívar. Mora dice que la tarea de Bolívar fracasó en la construcción de la unidad americana en cuanto a tener una sola voz y presencia unida ante el mundo, pero dejó un camino esperanzador. García Monge, como Bello, salvan "el eco bolivariano" con su conciencia del lenguaje y sus publicaciones. No quiere decir que Bolívar tampoco supo utilizar las "armas" del lenguaje.

Pero el problema de Bolívar fue la falta de claridad sobre el tipo de organización geopolítica, social e ideológica que se requería, siendo, como es América, tan heterogénea. Otro problema fue la falta de identidad, la falta de claridad acerca de quiénes eran las incipientes naciones frente a Inglaterra o Estados Unidos. Bolívar no pudo, dice Mora, aclarar qué clase de Estado era el idóneo: ¿nacional, regional, federal o centralizado? Había pueblos, no naciones; había dispersión, no instituciones... pero había conciencia del lenguaje y con él Bolívar tuvo conciencia del doloroso fragmentarismo y debilitamiento del cual se aprovechó el Imperialismo capitalista incipiente externo e interno. Termina Mora sentenciando: "Las fuerzas centrífugas fueron muy superiores a las fuerzas centrípetas..."

De nuestra parte se infiere asociado a la anterior opinión de Mora que el panorama de entonces no fue distinto del que lapidó la utopía humanista de García Monge luego de su muerte; aunque, desde entonces, se tiene el imperativo ético de recuperarla y de, objetivamente, criticarla para comprenderla; no solo para describirla de manera impresionista.

18. Martí logró la independencia de Cuba y propuso una visión política moderna, con lo que transitó muy adentro los caminos esbozados por Bolívar. De alguna forma, a través del lenguaje, tal como se señaló en García Monge y Bello, y de su estética con lo superó las limitadas políticas de Bolívar. La idea revolucionaria de Martí fue integral, ética y humanista en lo social, educativo, cívico, estético, político, científico, lo militar-liberador... No por casualidad vino a Costa Rica a buscar adeptos para su partido político, el cual llamo "Revolucionario". Esta diversidad fue un elemento de Vanguardia que hoy se puede identificar como posmoderna. Sin embargo, igual que sucedió con Bolívar y García Monge... sobrevino la fuerza centrífuga sobre la centrípeta hasta que llegó Fidel Castro a ponerle coto a esas fuerzas externas. 
ideológica, su Credo en el Porvenir-que resolverá los problemas de la Educación como lo dice en la conferencia "Unidos por la Cultura" (1944), demostró ser una Utopía y una Posibilidad Humanista aún por hacerse.

Sin embargo, estos problemas de la Educación más bien se profundizaron en el posmodernismo. Se pierde la idea de grandes fines y se instaura la inmediatez. La figura del Maestro ilustrado se cambia por la del especialista. Se banaliza su labor al instalarse la apatía en las aulas, el no-creerle al maestro es la consigna y con ello se anula su autoridad pedagógica. Aflora la desmotivación ante lo que se considera la "prédica aburrida y desfasada" del maestro. La juventud llamada a grandes cambios y esperanzas, según García Monge, no se aferra a nada porque nada le interesa más que "vivir" el gozo hedonista del ahora. Por eso, cuanto más se le pedía al alumno ilustrarse, leer, este menos lo hacía. Por eso, afirmé párrafos arriba que las juventudes conocían la existencia del Repertorio Americano aunque no todos lo leyeron profundamente. En suma, la moral elevada y humanista que pregonaba don Joaquín, para el cambio de época en los años cincuenta-sesenta, se convirtió en una ética de la negación del propio humanismo y en abono para el individualismo capitalista dominante.

Al decir de Flora Ovares y Seidy Araya (1986), a propósito de Mario Sancho, hay una oscilación entre el desencanto y la promesa, entre el escepticismo y la conciencia utópica sobre nuestro destino como pueblo.

\section{Bibliografía}

Aguirre, Carlos (1979). Algunas posibilidades del conocimiento en literatura, en Letras 1, abril-mayo-junio, Escuela de Literatura y Ciencias del Lenguaje, Universidad Nacional Autónoma, Heredia: EUNA.

Angulo, Francisco et al (2005). Cinco ensayos sobre Nuestra América. Cuadernos aportes teóricos de Nuestra América. 1 ed. Facultad de Filosofía y Letras, IDELA: Maestría en Estudios Latinoamericanos (POSTLATINO). Universidad Nacional Autónoma, Heredia, Costa Rica: EUNA.

Barrantes de Bermejo, Ana Cecilia (1996). América / España en el Repertorio Americano. Ministerio de Cultura, Juventud y Deportes, San José de Costa Rica: Editorial de la Dirección de Publicaciones.

(1981). Homenaje Continental a García Monge. Ministerio de Cultura Juventud y Deportes, San José, Costa Rica: Departamento de Publicaciones.

(1994) Istmica. Vol. 1. $\mathrm{N}^{\circ} 1$. Revista de la Facultad de Filosofía y Letras, Universidad Nacional Autónoma, Heredia, Costa Rica: EUNA.

Benjamin, Wálter (1980). Imaginación y sociedad. Iluminaciones 1. Madrid: Taurus Ediciones S.A.

Benjamin, Wálter (1980). Poesía y capitalismo. Iluminaciones 2. Madrid: Taurus Ediciones S.A.

Calderón Salas, Minor (2001). El legado cultural de José Martí, Joaquín García Monge y Jorge Luis Borges expresado en el Repertorio Americano. En 
Repertorio Americano, nueva época. $\mathrm{N}^{\circ}$ 11, enero-junio, Facultad de Filosofía y Letras, Instituto de Estudios Latinoamericanos (IDELA), Campus Omar Dengo, Universidad Nacional Autónoma, Heredia: EUNA.

Calvo, Yadira et alii (1990). Mitos y realidades de la democracia en Costa Rica. San José, Costa Rica: Editorial Departamento Ecuménico de Investigaciones.

Carpentier, Alejo (1981). La novela latinoamericana en vísperas de un nuevo siglo y otros ensayos. México: Siglo Veintiuno Editores S. A.

Collazos, Óscar et al (sfe). Literatura en la revolución y revolución en la literatura. México: Siglo Veintiuno Editores S. A.

Chase B., Alfonso et al (1974). Obras escogidas Joaquín García Monge. San José, Costa Rica: EDUCA.

Chase B, Alfonso (1997). Los herederos de la promesa. San José, Costa Rica: ECR.

Cuevas Molina, Rafael (1995). El punto sobre la i. Políticas Culturales en Costa Rica (1948-1990). Edición Conmemorativa XXV Aniversario de la Creación del Ministerio de Cultura, Juventud y Deportes (1971-1996). 1 ed. Ministerio de Cultura Juventud y Deportes, San José, Costa Rica: Departamento de Publicaciones.

Cuevas Molina, Rafael (2006). Cultura y Política en Costa Rica. Entrevistas a protagonistas de la política cultural en la segunda mitad del siglo XX. Universidad Estatal a Distancia, San José, Costa Rica: EUNED.

Dengo Obregón, María Eugenia. (2007) Omar Dengo Guerrero: escritos y discursos. Universidad Nacional Autónoma, Heredia, Costa Rica: EUNA.
Donoso Pareja, Miguel (1976) Literatura refleja y colonialismo cultural, en Revista Cambio, $N^{\circ} 21$, enero-marzo, México: Editorial Extemporáneos.

Durán Luzio, Juan (1979). Creación y utopía: letras de Hispanoamérica. Heredia: EUNA.

Durán Luzio, Juan (2003) Senderos de Identidad (diez ensayos sobre literatura costarricense). San José, Costa Rica: ECR.

Fernández Retamar, Roberto (1975). Para una teoría de la literatura hispanoamericana $y$ otras aproximaciones, en Cuadernos $C A S A$, número 16, La Habana, Cuba: Ediciones Casa de las Américas.

Ferrero, Luis (1978). La clara voz de Joaquín García Monge. San José: Editorial Costa Rica.

Ferrero, Luis (1988). Pensando en García Monge. San José: Editorial Costa Rica.

García Carrillo, Eugenio (1962). Cosas de Don Joaquín. San José, Costa Rica: Editorial Trejos Hns.

García Monge, Joaquín (1901). El Moto. Barcelona, España: Padrón y Pujol.

García Monge, Joaquín (1905). El arado y la pluma, en Revista La Siembra, mayo 25, San José de Costa Rica.

García Monge, Joaquín (1944). El artista, el ideal y la belleza. Discurso inédito de recepción del Premio María Moors Cabot. Universidad de Columbia, Nueva Cork, Estados Unidos de Norteamérica.

González Stephan, Beatriz (1987). La historiografia literaria del liberalismo hispanoamericano del siglo XIX. La Habana, Cuba: Ediciones Casa de las Américas.

Herrera, Fernando (compilador) (2004). Joaquín García Monge: ensayos de juventud. San José, Costa Rica: Editorial Costa Rica. 
Herrera, Fernando (1995). Presencia de Chile en Joaquín García Monge: un capitulo de su vida. En Nuevo Humanismo, segunda época. $\mathrm{N}^{\circ} 4$, II semestre 1995 - I semestre 1996, Centro de Estudios Generales, Campus Omar Dengo, Universidad Nacional Autónoma, Heredia: Editorial Fundación UNA.

Hurtado, Gerardo César (1987). Novela y sociedad en Costa Rica y Centroamérica (Análisis y proyecciones), en Letras 2122, enero-junio, Escuela de Literatura y Ciencias del Lenguaje, Universidad Nacional Autónoma, Heredia: EUNA.

Molina Jiménez, Iván (2007). Anticomunismo reformista. Competencia electoral y cuestión social en Costa Rica (1931-1948). 1 ed. San José: Editorial Costa Rica.

Molina Jiménez, Iván (2005). Demoperfectocracia. La democracia pre-reformada en Costa Rica (1885-1948). Universidad Nacional Autónoma, Heredia, Costa Rica: EUNA.

Molina Jiménez, Iván y Palmer, Steven (2003). Educando a Costa Rica. Alfabetización popular, formación docente y género (1880-1950). Universidad Estatal a Distancia, San José, Costa Rica: EUNED.

Molina Jiménez, Iván y Palmer, Steven (2005). El paso del cometa. Estado, política social y culturas populares en Costa Rica (1800-1950). Universidad Estatal a Distancia, San José, Costa Rica: EUNED.

Monge, Carlos Francisco (2005). El vanguardismo literario en Costa Rica. Heredia: EUNA.

Mora Rodríguez, Arnoldo (2008). El arielismo de Rodó a García Monge. Universidad Estatal a Distancia, San José, Costa Rica: EUNED.

Mora Rodríguez, Arnoldo (2006). La filosofia latinoamericana. Introducción histórica.
Universidad Estatal a Distancia, San José, Costa Rica: EUNED.

Morales M, Carlos et al (1996). El ideario de Don Quijote (compilación). Cuaderno Prometeo $\mathrm{N}^{\circ} 16$. Departamento de Filosofía, Universidad Nacional Autónoma, Heredia: EUNA.

Morales, Gerardo (1993). Cultura oligárquica y nueva intelectualidad en Costa Rica. Universidad Nacional Autónoma, Heredia: EUNA.

Núñez M., Francisco María, (1974). Mi tierra nativa. Edición Facsímil de la de 1917, Desamparados, Costa Rica: Editorial Adecas (E. A).

Núñez M., Francisco María (1967). Desamparados tierra nutricia (paisajes, hombres, documentos). Edición dirigida por Gabriel Ureña, Desamparados, Costa Rica: Editorial Adecas (E. A).

Ovares, Flora et alii (1993). La casa paterna: escritura y nación en Costa Rica. San José: EUCR.

Ovares, Flora y Rojas, Margarita (1995). Cien años de literatura costarricense. San José, Costa Rica: Ediciones Farben.

Ovares, Flora y Araya, Seidy (1986). Mario Sancho, el desencanto republicano y su proyecto de Patria. San José, Costa Rica: Editorial Costa Rica.

Ovares, Flora y Araya, Seidy (1987). Mario Sancho y su proyecto de patria, en Letras 21-22, enero-junio, Escuela de Literatura y Ciencias del Lenguaje, Universidad Nacional Autónoma, Heredia: EUNA.

Ovares, Flora y Vargas, Hazel (1982). Trinchera de ideas. Heredia, Costa Rica: EUNA. 
Ovares, Flora y Rojas, Margarita (1995). Cien años de literatura costarricense. San José, Costa Rica: Ediciones Farben.

Oyamburu, Jesús y González, Miguel A, coordinadores (1997). Cambio de época y producción cultural desde Costa Rica. 1 ed. Embajada de España, Centro Cultural Español - ICI, San José, Costa Rica.

Quesada Monge, Rodrigo (2001). El legado de la guerra hispano-antillananorteamericana.

Quesada Monge, Rodrigo (1992). América Latina y el mundo contemporáneo, tercer periodo 1962-1990. Antologia de historia de la cultura. Universidad Estatal a Distancia, San José, Costa Rica: EUNED.

Quesada Soto, Álvaro (1986). La formación de la narrativa nacional costarricense (18901910), enfoque histórico social. Universidad de Costa Rica, San José: EUCR.

Ramírez G., Ángela (2006). Posmodernidad y politica, en Revista Espiga julio-diciembre, $\mathrm{N}^{\circ} 12$, Escuela de Ciencias Sociales y Humanidades, Universidad Estatal a Distancia, San José, EUNED.

Rodríguez Vega, Eugenio (2001). Cinco educadores en la Historia. Universidad Estatal a Distancia, San José, Costa Rica: EUNED.

Rojas Osorio, Carlos (2004). Posmodernismo $y$ educación moral, en Revista Espiga julio-diciembre, $\mathrm{N}^{\circ} 10$, Escuela de Ciencias Sociales y Humanidades, Universidad Estatal a Distancia, San José, EUNED.

Salazar Bondy, Augusto (1985). ¿Existe una filosofía de nuestra América? México: Siglo Veintiuno Editores S. A.

Sartre, Jean Paul (1997) El existencialismo es un humanismo. San José, Costa Rica: Editorial Guayacán.

Savater, Fernando (2000). Humanismo impenitente. 2 ed. Barcelona: Editorial Anagrama, S. A. 